\title{
AVO analysis for high amplitude anomalies using 2D pre-stack seismic data
}

\author{
Lamees N. Abdulkareem \\ Department of Earth science, College of Science \\ University of Baghdad, Baghdad, Iraq \\ Corresponding Author: lamees.nazar@sc.uobaghdad.edu.iq
}

\begin{abstract}
Amplitude variation with offset (AVO) analysis is an efficient tool for hydrocarbon detection and identification of elastic rock properties and fluid types. It has been applied in the present study using reprocessed pre-stack 2D seismic data (1992, Caulerpa) from the northwest of the Bonaparte Basin, Australia. The AVO response along the 2D pre-stack seismic data in the Laminaria High NW shelf of Australia was also investigated. Three hypotheses were suggested to investigate the AVO behavior of the amplitude anomalies in which three different factors; fluid substitution, porosity, and thickness (Wedge model) were tested. The AVO models with the synthetic gathers were analyzed using log information to find which of these is the controlling parameter on the AVO analysis. AVO cross plots from the real pre-stack seismic data reveal AVO class IV (showing a negative intercept decreasing with offset). This result matches our modelled result of fluid substitution for the seismic synthetics. It is concluded that fluid substitution is the controlling parameter on the AVO analysis and therefore, the high amplitude anomaly on the seabed and the target horizon 9 is the result of changing the fluid content and the lithology along the target horizons. While changing the porosity has little effect on the amplitude variation with an offset within the AVO cross plot. Finally, results from the wedge models show that a small change in thickness causes a change in the amplitude; however, this change in thickness gives a different AVO characteristic and a mismatch with the AVO result of the real 2D prestack seismic data. Therefore, a constant thin layer with changing fluids is more likely to be the cause of the high amplitude anomalies.
\end{abstract}

Keywords: AVO analysis; fluid substitutions; high amplitude anomalies; laminaria High NW shelf of Australia; wedge model.

\section{Introduction}

AVO (Amplitude variation with offset) attributes can be used to analyze the type of fluids that cause amplitude anomalies by using pre-stack seismic data. It is a commercial tool for hydrocarbon detection (Foster et al., 2010), drilling risk (Guan et al., 2018), and identifying elastic rock properties and fluid types (Wandler et al., 2007). High amplitude anomalies on the seabed and at near-surface horizons have been recognized in the Laminaria High (Figure.1a) as an indication of hydrocarbon leakage (Langhi et al. 2010 and Abdulkreem et al. 2019). These amplitude anomalies (bright spots) are associated with the Cenozoic fault network (Figure 1. b) which was reactivated due to the oblique 
collision between the Australian and Eurasian plates in the late Miocene-Pliocene and caused hydrocarbon leakage (Gartrell et al., 2003; Gartrell et al., 2004; Gartrell and Lisk, 2005; Gartrell et al.,2006; Langhi et al., 2011). Many structural and trap integrity studies have investigated the cause of hydrocarbon leakage, dry wells, and fault reactivation in the Laminaria High (De Ruig et al.,2000; Gartrell et al.,2005; Dyt et al., 2012; Ciftci and Langhi.,2012; Saqab et al.,2015; Saqab et al.,2017) and other studies have investigated the mechanism behind the lack of hydrocarbons and estimate the hydrocarbon charge (Abbassi et al., 2015). However, no studies have been carried out in this study area to analyze the amplitude anomalies using AVO attributes and to confirm the origin of these anomalies (bright spots). To resolve this, this study has involved re-processing of 2D pre-stack seismic data to investigate the existence of the high amplitude anomalies that have been recognized on the 3D stacked time migrated data in the Laminaria high (Langhi et al. 2010 and Abdulkareem et al., 2019). The existence of hyrocarbons has been discriminated and the AVO behavior of the high amplitude anomalies or bright spots has been confirmed. Also, for this study, three factors (fluid substitutions, porosity, and thickness (wedge model)) were analyzed to identify the controlling factor on AVO behavior (Loizou et al.2008; Montazari, 2013; Sadeq et al.,2014; Bakhtiari et al., 2014; Saeed et al., 2020).

\section{Geological setting}

The Laminaria High is located in the northern part of the Bonaparte Basin (Figure.1a); it is close to the edge of the Timor Sea. It is a small east-west oriented part of a remnant platform, surrounded by the Nancar and Cartier Trough to the south and Flamingo syncline to the east (Smith et al, 1996 in Langhi et al, 2008). Reactivation of a Jurassic fault system (De Riug et al., 2000) is attributed to the collision that happened in the late Miocene- Pliocene between the Australian plate and the SE Asian plate. The stratigraphy of the Laminaria High in the Bonaparte Basin was affected by the Mesozoic rifting and passive margin phase. The Plover Formation, which is Lower to Middle Jurassic in age, is a very thick sand-dominated fluvial and deltaic unit showing the pre-rift sequence (Abbassi et al., 2015 ). The Laminaria Formation is the reservoir section (Oxfordian to Callovian). This Formation consists of massive sandstone with minor interbedded claystone. The Frigate Formation (OxfordianKimmeridgian), Flamingo (Tithonian-Berriasian), and Echuca Shoals (Valanginian-Barremian) covered the Laminaria Formation and represent the open marine shaly formations. The Johnson, Hibernia, Prion, Cartier, Oliver, and Barracouta Formations are the seal section (Mesozoic sequence) which comprises shale and silty claystone. These formations are covered by calcarenites and calcilutite, which show extensive coverage of the carbonate deposits (Abbassi et al. 2015)

\section{AVO principles}

AVO analysis is a commercial tool for hydrocarbon detection; it is used to identify elastic rock properties and fluid types (Wandler et al. 2007). In addition, AVO anomalies result from the change in acoustic impedance of the seismic reflector Chopra and Castanga, 2014). Fundamentally, AVO behavior depends on the i) AVO intercept (A) (or Reflection coefficient) and the slope or gradient (B) 
cross plot (Eq.1), and ii) the variation in density $\rho$, P-wave velocity $\mathrm{V} p$ and S-wave velocity Vs (Castagna, 1997). The main outputs from AVO analysis are to identify the AVO class (Foster and Keys, 1999; Castagna and Swan, 1997) and the existence of hydrocarbons (Ross and Kinmann, 1995; Verm and Hilterman, 1995).

$R(\theta)=A+B \sin 2 \Theta$ (Shuey's Approximation to the Zoeppritz equation) eq.1

$\mathrm{R}=$ reflection coefficient

$\theta=$ angle of incident

$\mathrm{A}=\mathrm{AVO}$ intercept

$\mathrm{B}=\mathrm{AVO}$ gradient

Rutherford and Williams (1989) have divided the AVO response of gas-sand reflections into three classes (class I, II, and III) based on the location of the normal reflection coefficient. B is the gradient and $\mathrm{R} 0$ is the intercept (A) (zero offset reflection coefficient). A fourth AVO class (IV) has been added by Castagna and Swan (1997), which is useful in identifying thin layers. on the location AVO anomalies could appear as bright spots, flat spots, and dim spots which are considered to be hydrocarbon indicators; conversely, these anomalies could also be an indication of lithology variations.
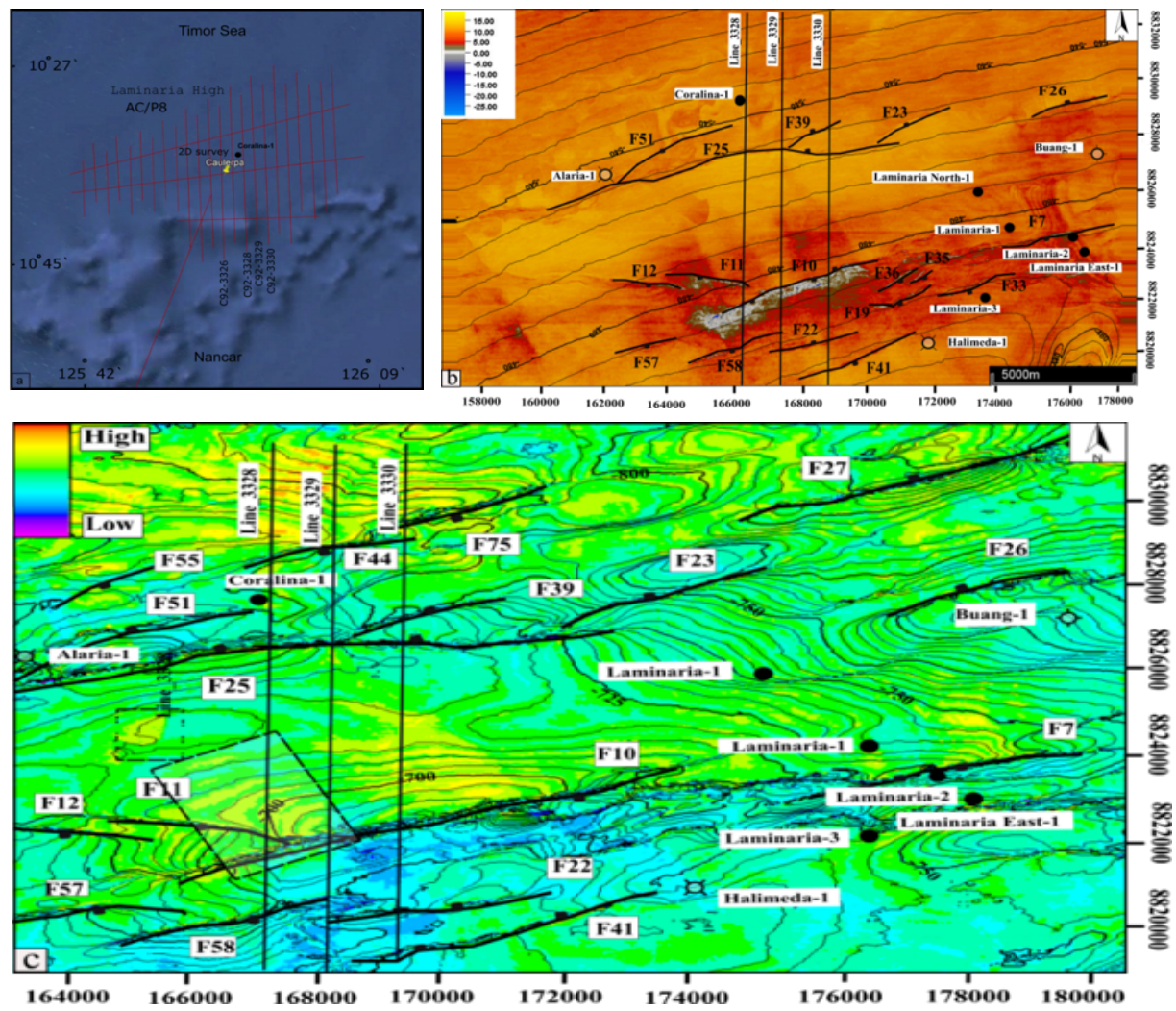

Fig.1. a) Location map of the study area showing the four 2D seismic lines that have been processed in this study. b) Amplitude horizon map of the seabed showing the location of the high amplitude anomaly and the three 2D seismic lines that cross the study are c. RMS amplitude horizon map with two-way time structure contours for Horizon A. The black box indicates the amplitude anomalies associated with fault 10, from (Abdulkareem et al.,2019) 
The Caulerpa 2D pre-stack seismic data (1992) used in this study was acquired by Western Geophysical Company, and the survey was conducted by Woodside Offshore Petroleum LTD. This survey consists of 27 lines that cover about $675 \mathrm{Km} 2$ within the $\mathrm{AC} / \mathrm{P} 8$, northwest of the Bonaparte Basin. The digital streamer is about $4000 \mathrm{~m}$ with 240 channels, group interval from 1-180 is $13.3 \mathrm{~m}$ and from $180-240$ is $26.6 \mathrm{~m}$. A series of seismic processing procedures have been applied previously on these data. Four 2D lines were processed: C92-3326, C92-3328, C92-3329, and C92-3330 (Figure 1a). In this paper, AVO analysis focused on the 2D line C92-3328 (28.61 km in length), which is located near to well Coralia-1, as this line crosscuts the high amplitude anomaly on the seabed map as shown in Figures 1 $a$ and $b$. Geoscience Australia supplied a set of good data (LAS files and composite images of logs). In this study, we used density log (Rho), Gamma log, and Vp logs from well Coralina-1. For this study, Vshale, Vs, and porosity logs were extracted from gamma, Vp, and density logs

\section{Methodology}

\subsection{Seismic processing for AVO analysis}

Reprocessing for the 2D was done using Globe Claritas V6.2.11 software. Seismic processing includes attenuation of the noise, enhancing the signal, and migrating seismic events to their actual location in space. To prepare the pre-stack data for AVO analysis, extra processing steps are required. The principal steps to achieve the desired result include 1) deconvolution; 2) pre-stack migration; 3) F-K filter 4) Offset to angle gathers. To improve the resolution of the seismic data, deconvolution was applied to the pre-stack data. This process compresses the seismic wavelet towards a spike by whitening the frequency spectrum and hence improves the resolution. In addition, it recovers the higher frequencies, attenuates short-period multiples, and generates a zero-phase wavelet that is easier for interpretation (Yilmaz, 2001). After applying the deconvolution filter, pre-stack time migration is applied. This process is very useful to get a better image of the stacked data as it removes the effect of dipping layers and refraction waves (Figures $2 \mathrm{a}$ and b). F-k filtering is then applied to maintain the low frequency of the reflected wave and remove unwanted signal noise and aliased surface waves (Figures 3a, b, c, and d).

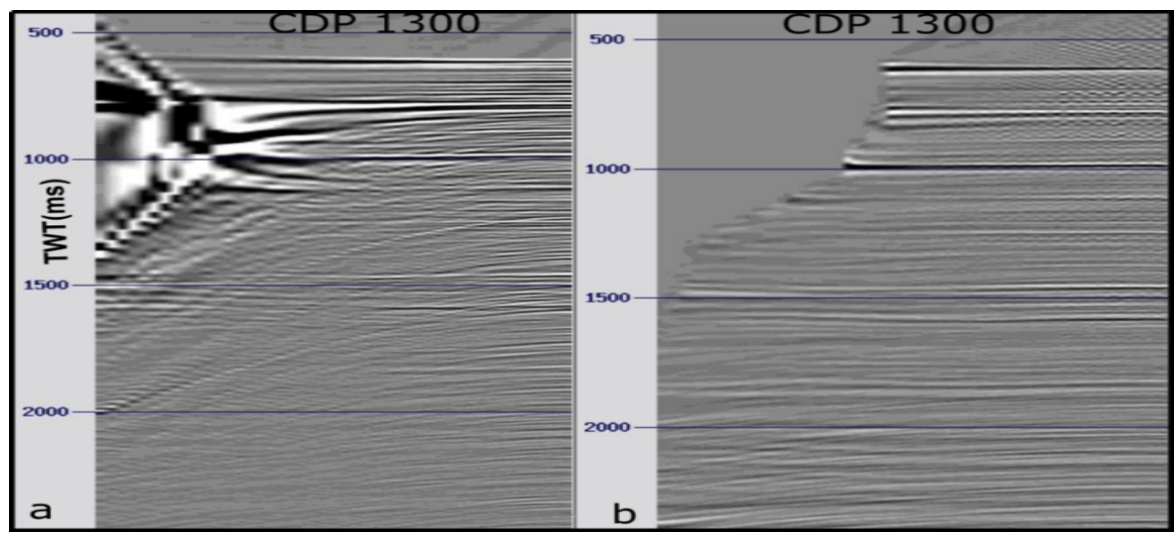

Fig. 2. a. CDP (1300) gather before pre-stack time migration; b. CDP (1300) gather after pre-stack time migration. Note: the effect of dipping layers and refraction waves are removed, and the reflectors are flattened. 

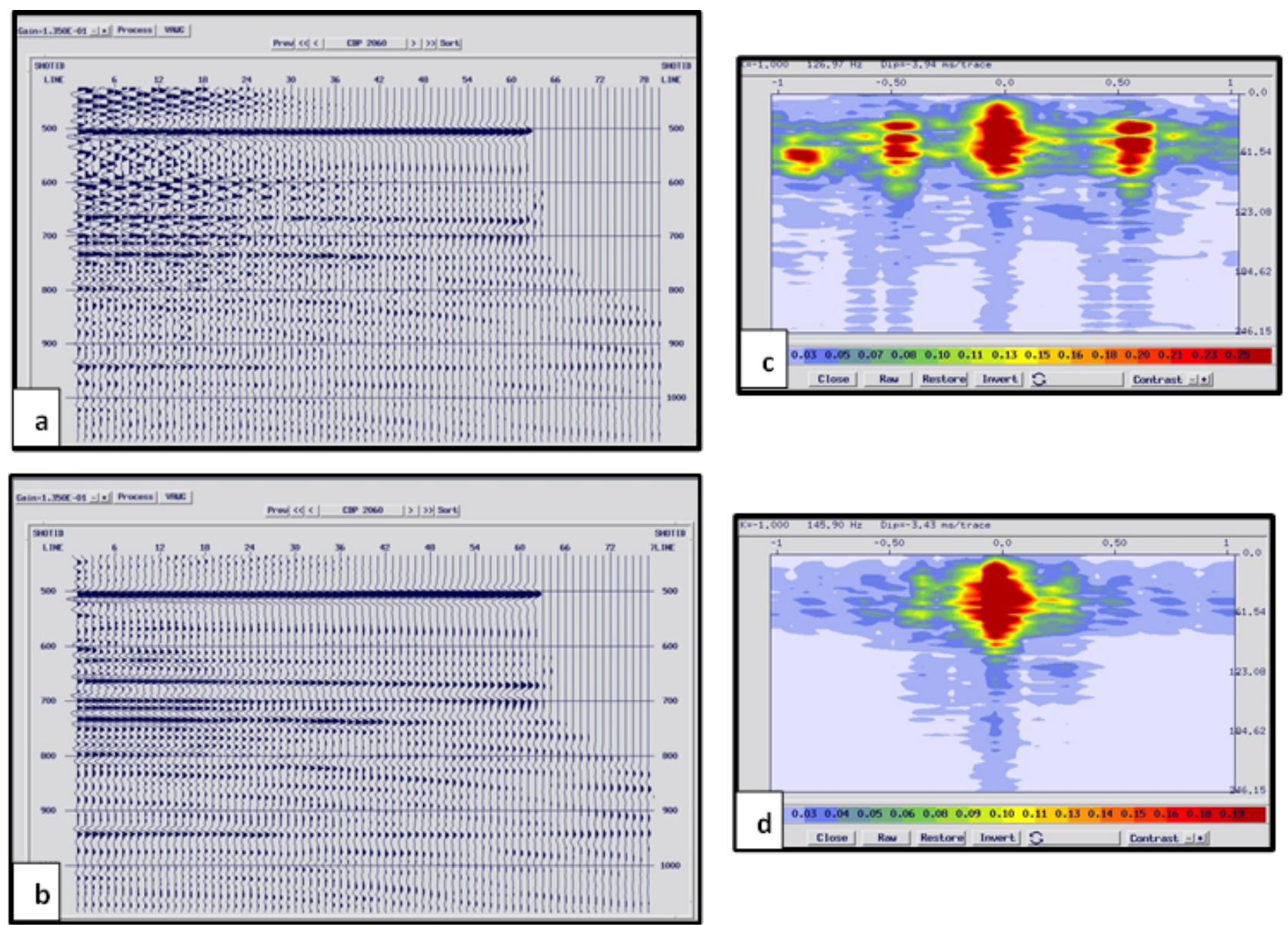

Fig. 3. a CDP (2060) gather before applying F.K filter; b. CDP(2060) gather after applying F.K. filter. c. the signal noise is shown on the sei smic CDP gathers before applying F.K filter; $d$. the signal noise is removed from the seismic CDP gathers after applying F.K. filter

Finally, the offset CDP gathers are converted into angle gathers by applying for the Angle job in Claritas as shown in (Figures $4 \mathrm{a}$ and $\mathrm{b}$ ); the CDP gathers are flattened to apply the AVO analysis around the interesting zones. AVO analysis was first applied to the raw pre-stack data (Line- C923328) and second, AVO was applied using RocDoc software. Results of the AVO analysis were then compared and discussed.

\subsection{AVO analysis of the real prestack data using Claritas:}

AVO analysis was applied from sqc application in Claritas by choosing a CDP gather that includes the interesting anomalies. The AVOSTACK processer takes the CDP gathers with the corrected NMO (Normal Moveout) and outputs AVO attributes. In our study AVA (Amplitude Variation with Angle) attributes are displayed. AVO analysis was applied along two specified horizons (seabed and Horizon 9) (Figure 1. a and b) that show high amplitude anomalies, resulting in amplitude variation vs offset plots. 


\subsection{AVO analysis using RocDoc software}

For AVO analysis, the required well data, Vp, Gamma, and density logs were imported, in addition to Vs, Vshale, and porosity logs which were extracted from previous logs (Figure. 5a). A wavelet was extracted to generate the synthetic gather (Figure. 5b) used

for the AVO analysis. Vp-Vs - Rho logs were grouped in one set to choose them all together as an input in the AVO function. Fluid effects on the seismic velocity and the density were modelled using Gassmann's equations for different fluid saturation (Han and Batzle.,2004). Synthetic gathers with different fluid content (oil and Gas) were generated using the Vp-Vs-Rho Ratio. The cross plots from each gather were then used to extract the AVO attribute which includes the intercept (A) and gradient (B) that represent the amplitude variation with offset. After extracting the synthetic gather from good logs, a working interval was created that represents the target horizons and fluid substitution analysis was applied with a specific percentage of oil and gas.
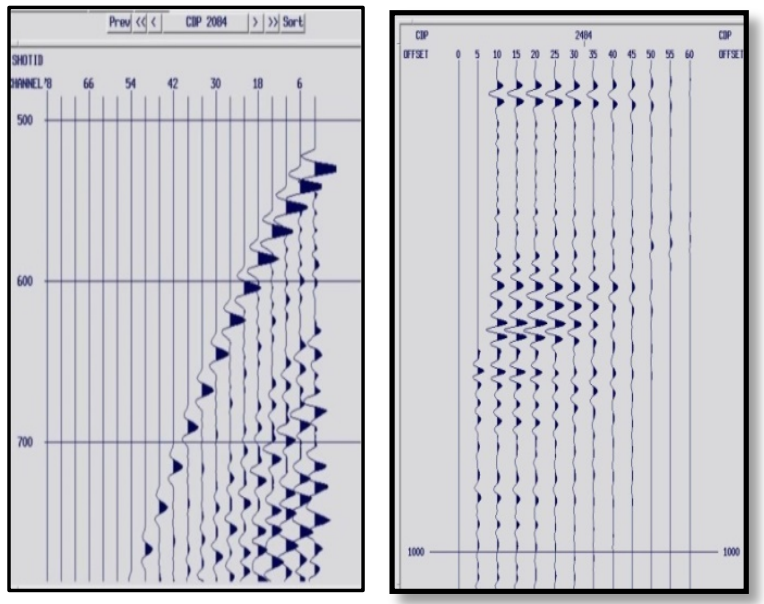

Fig. 4. a.offset CDP (2084) gathers; b. angle CDP (2084) gathers
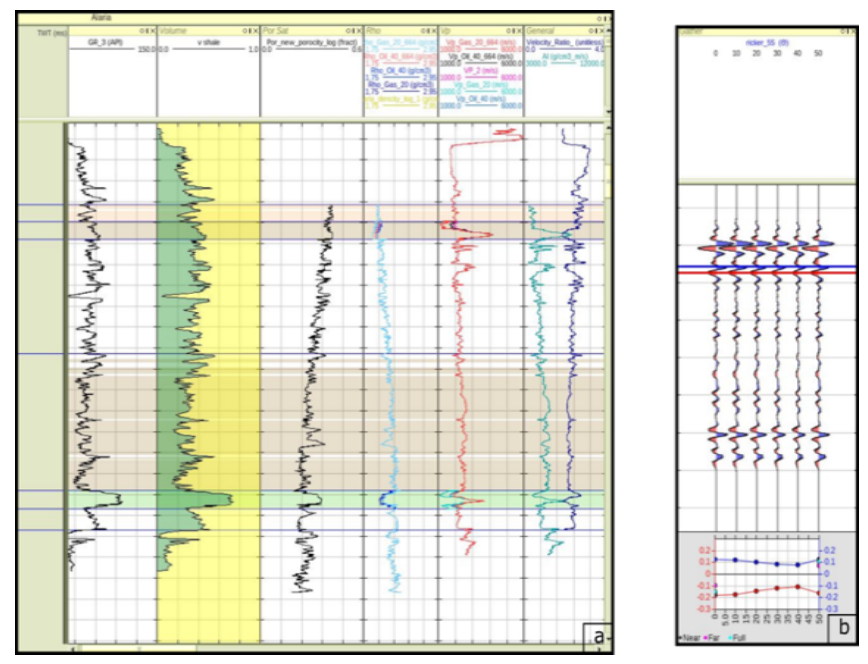

Fig. 5. a. set of the logs that were used in the AVO analysis which include (Rho, Gr, porosity, Vp and Vs) b.Initial synthetic gather extracted from Ricker wavelet (55) to be used in the AVO analysis.

\section{Results and discussion}

6.1 Comparison between AVO behavior in real data and synthetic models

Two horizons (Seabed and Horizon 9) were the central focus of this study in investigating AVO behavior for high amplitude anomalies along these horizons. Three ranges of CDP gathers were chosen along horizon 9, 2060-2330; 2550-2830; 2900- 3120 and the CDP range for the seabed were 12101950 as shown in figures $1 \mathrm{~b}$ and $\mathrm{c}$. These ranges were chosen as they crosscut the high amplitude anomalies along the two horizons. Amplitude variations with offset (CDP) at Horizon 9 and the seabed for the chosen CDP gathers were plotted as shown in (Figures 6a and b ). These figures show the cross plot of intercept (A) reflection coefficient (Ro) and gradient or slope (B). The amplitude is decreasing 
with offset as it shows negative intercept decreasing with offset. AVO results from real seismic data in Claritas were displayed and compared with AVO results from RocDoc. The AVO cross plot from the real seismic data matches the AVO cross plot from the synthetic models in RockDoc as it shows class $\mathrm{IV}$ at horizon 9 in Figures $7 \mathrm{a}$ and $\mathrm{b}$ and Figures $8 \mathrm{a}$ ad $\mathrm{b}$.

\subsection{Parameters that control AVO behaviour.}

In this study, three hypotheses were suggested to investigate the AVO behavior of the amplitude anomalies. Three different factors were tested and the synthetic gathers were analyzed using log information from Coralina-1 well data, to find which of them is the controlling parameter on the AVO analysis. These factors include:

- $\quad$ fluid flow (fluid Substitutions).

- $\quad$ porosity.

- the thickness of the layers.

\subsubsection{Fluid Substitutions}

The first hypothesis involved testing the impact of fluid substitution or saturation on AVO behavior within the target horizons. For this model, the Gassmann theory was used (Smith et al., 2003). Fluid substitution modeling determines the effect of changing fluids and the variation of petrophysical properties (fluid saturation) on Vp, Vs, and density (Rho) based on Gassmann's equation 1951:

$$
K=K_{d r y}+\frac{\left(1-\frac{K_{d r y}}{K_{m}}\right)^{2}}{\frac{Q}{K_{f}}+\frac{1-Q}{K_{m}}+\frac{K_{d r y}}{K_{m}^{2}}}
$$

$\mathrm{K}$ is bulk modulus of reservoir rock; $\mathrm{K}_{\mathrm{dry}}$ and $\mathrm{K}_{\mathrm{f}}$ are bulk modulus of dry rock; $\mathrm{K}_{\mathrm{m}}$ is bulk modulus of mineral content in the rock; $\mathrm{Q}$ is the porosity.

Inputs for this model included the target zone for fluid substitution; the Vp,Vs, Rho and porosity logs (porosity was constant in this model); fluid saturation of the water $\left(\mathrm{S}_{\mathrm{w}}\right)$, oil $\left(\mathrm{S}_{\mathrm{o}}\right)$ and gas $(\mathrm{Sg})$ and mineral values (sued the default set). Dry rock properties (bulk modulus) were constant during running the fluid substitution model (Smith et al. 2003).

Different synthetic models were extracted from well logs with different percentage fluid (oil and gas) saturation as shown in Figures 9.a and b. In this model, we focused on horizon 9. The brine content was substituted with $40 \%$ oil and $5 \%$ gas and two synthetic gathers were generated to extract the AVO model. AVO cross plots reveal AVO class IV because of fluid substitution and we have a negative intercept decreasing with offset (Figure $11 \mathrm{a}$ and $\mathrm{b}$ ). This matches the AVO result from the real seismic data, which also shows a negative intercept decreasing with offset (Figures 6 and 7).

Overall, results indicate that the AVO cross plots (Figure 9a and b) are sensitive to changes in fluid type and saturation. Therefore, this analysis (fluid substitution) confirms that the amplitude anomalies are controlled by fluid type or fluid content. The seismic response to the change in rock properties and fluid content was confirmed using fluid substitution modelling (Rizwan et al.,2018; Mughal and Akhter,2020; Arun et al.,2020). By analogy, the amplitude anomalies on horizon 9 were interpreted as 
an indication of hydrocarbon leakage (Langhi et al. 2010 and Abdulkreem et al. 2019) and these results are confirmed by fluid substitution models and AVO cross plots.
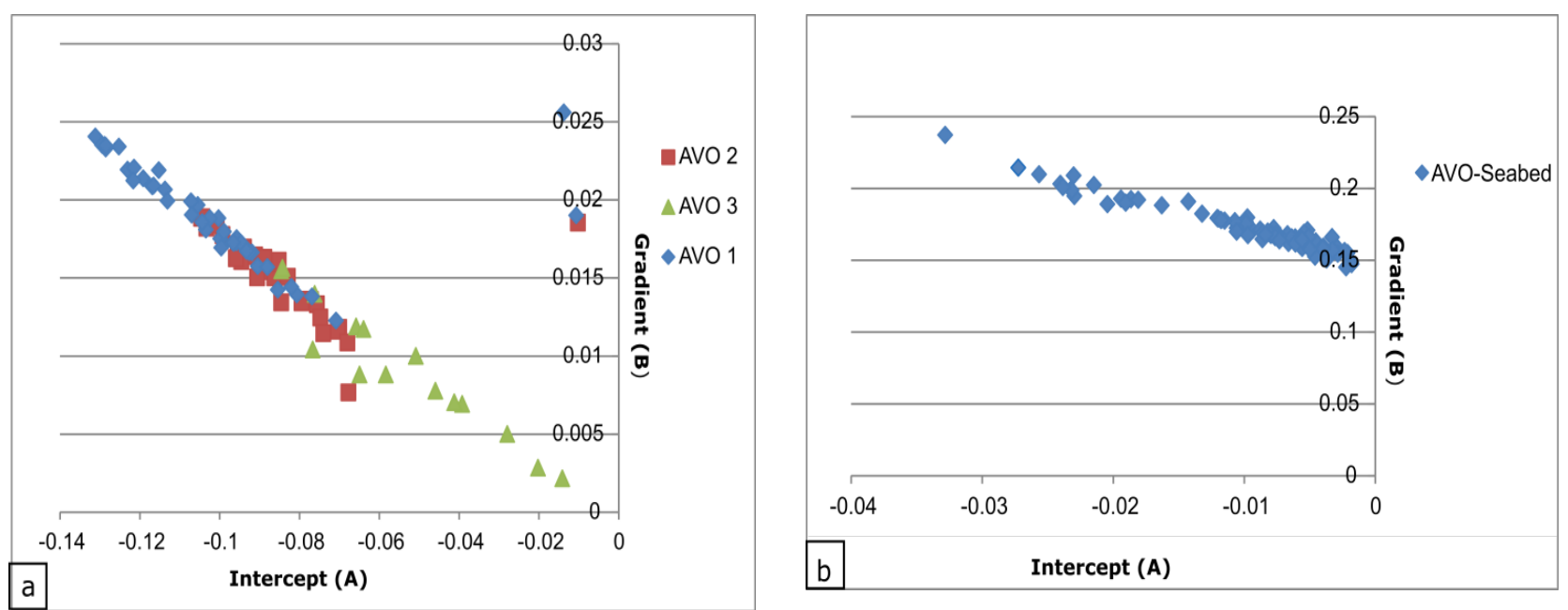

Fig. 6. $a$ and $b$ shows cross plot of intercept (A) reflection coefficient (Ro) and gradient or slope (B). Note: the amplitude is decreasing with offset as it shows negative intercept decreasing with offset.
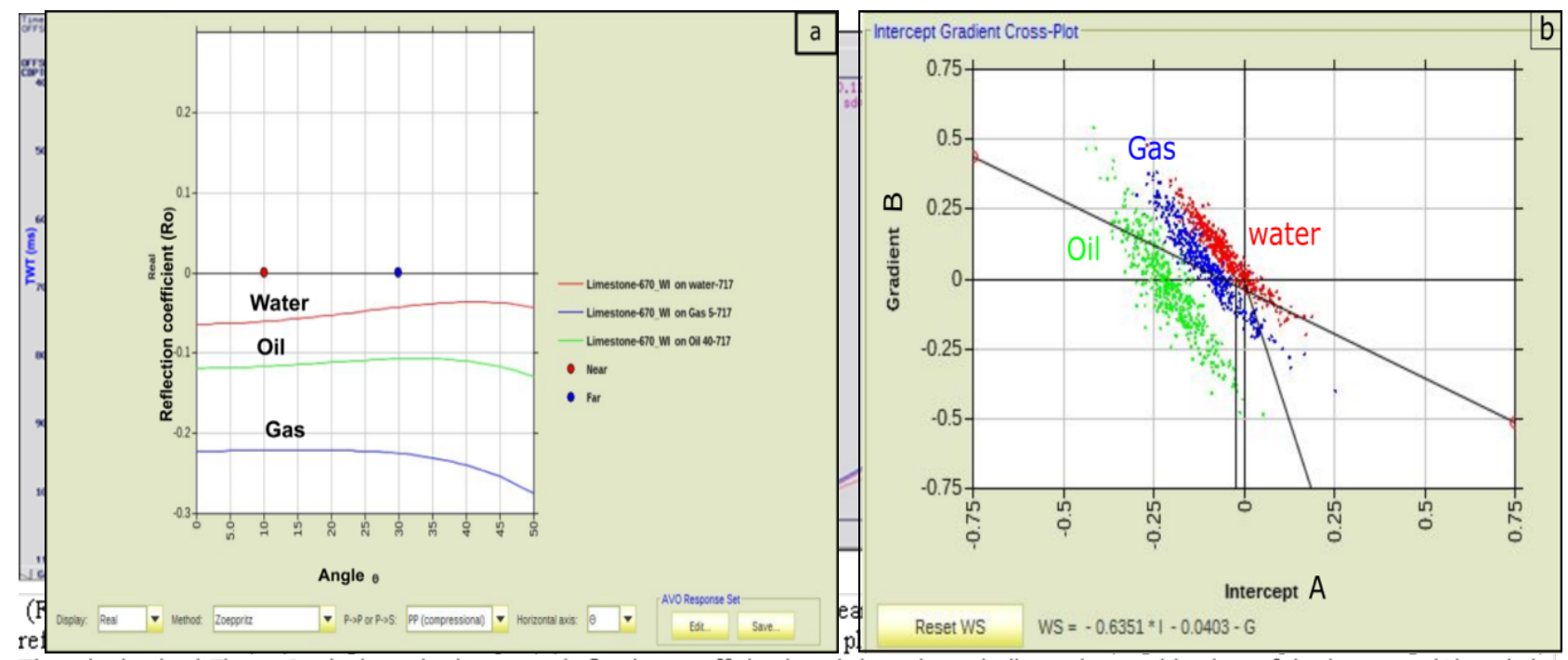

The wiggles in ( Figure 8a ) show the intercept (reflection coefficient) and the colours indicate the combination of the intercept (A) and the gradient (R)

Fig. 8. a. AVO plots show the Reflection coefficient (R0) variation with angle $\Theta$ within the target horizon-9. Note: AVO is showing class IV and the reflection coefficient is decreasing with offset; $b$. Intercept-Gradient cross plot at horizon-9 for the synthetic model. 


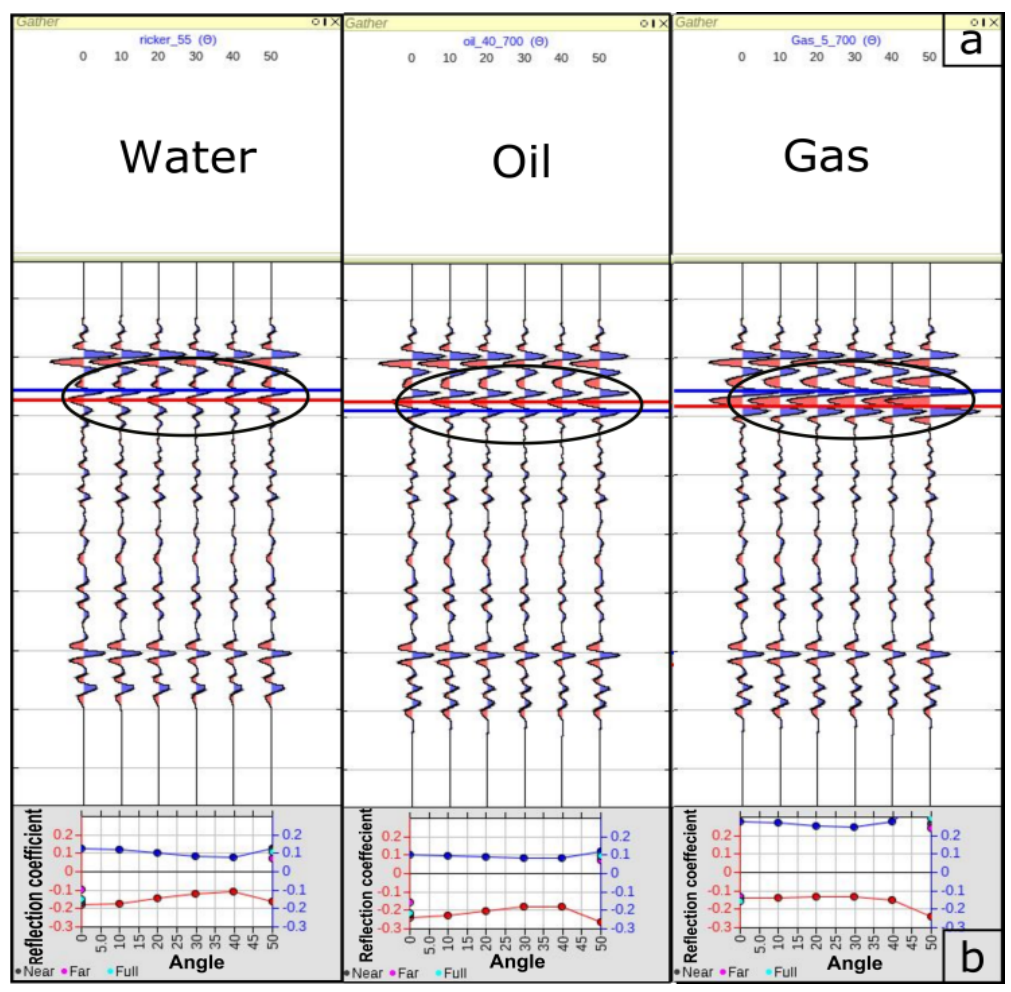

Fig.9. a. Synthetic gathers for fluid Substitutions (Water, $40 \%$ oil and $5 \%$ gas). b. cross plot shows the Reflection coefficient (R0) variation with angle $\Theta$ within the target horizon 9.

\subsubsection{Porosity}

The second hypothesis involved testing the porosity. The porosity log was calculated from the density log. Lithology at the target zone (Horizon 9) consists of carbonates and layers of sand and shale; the differentiation of carbonate layer is complicated in seismic interpretation. This is because of the heterogeneity of carbonate porosity ( $\mathrm{Li}$ and Downton,2003). AVO analysis helps to understand the relationship between carbonate rock properties and the sensitivity of fluid and porosity to rock properties. In this model, we tested the effect of changing porosity on the density, Vp and Vs (Susan et al,1990) and investigated its effect on the AVO behaviour in the synthetic models. First, porosity is changed in a range of $-/+$ 0.1-0.2 within the target horizon (New Vp-Vs-Rho ratios were then created with the new porosity values (Figure 10). AVO plots in Figure 11 show that changing the porosity has little effect on the amplitude variation with offset which gives the same AVO behaviour, a negative intercept decreasing with offset (Figures $11 \mathrm{a}, \mathrm{b}$ and c). In addition, the ratio of $\mathrm{Vp} / \mathrm{Vs}$ is a constant of a value of 0.998 . This result is consistent with previous studies of carbonate rocks (Chako,1989). 


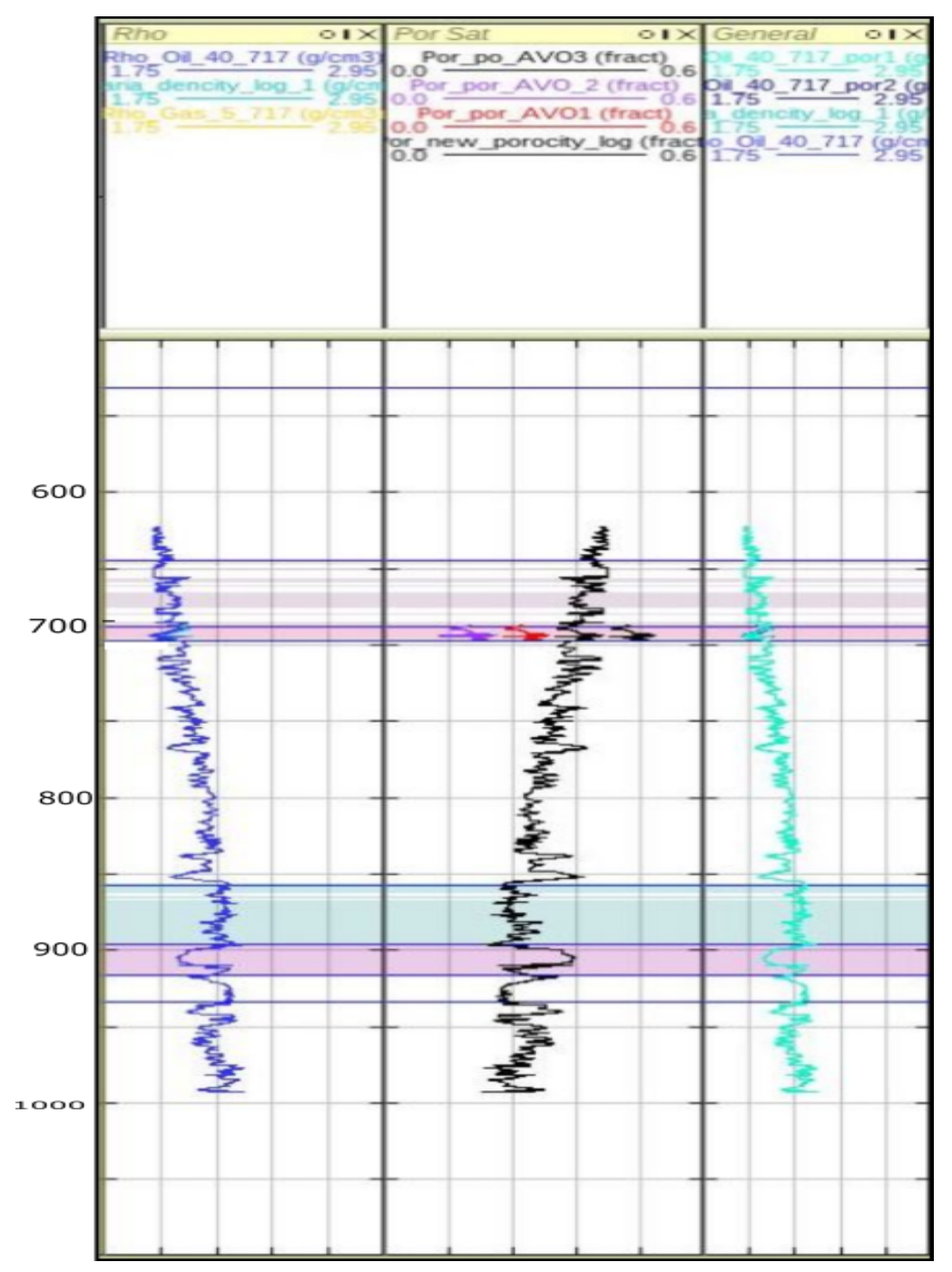

Fig. 10. Density, Porosity log and the new porosity logs by changing the porosity in a 6.2 .3 range of $-/+$ 0.1-0.2 within the target horizon and the new $\mathrm{Vp}-\mathrm{Vs}-\mathrm{Rho}$ ratios extracted from the new porosity values.

Thickness (Wedge model)

The third hypothesis suggests that AVO variation is controlled by changing the thickness of the layers. The thickness of any geologic layer affects the seismic amplitude which in turn could affect the result of AVO behaviour (Pan and Innanen,2013; Farfour et al,2015; Saeed et al., 2020). To test this hypothesis, the wedge model was used in integration with the AVO analysis to investigate the effect of tuning thickness (thin beds) on the amplitude anomalies (Widess, 1973; Puryear and Castagna, 2008). 
In this model we built 3 wedge models by changing the fluid content (water, oil and gas) (Figures 12 a,b and c ) and using the ricker 55 wavelet and GR, Vp, Vs, Rho and Porosity logs. A small change of thickness caused a change in the amplitude; however, this change in thickness gave different AVO characteristics (Figures $13 \mathrm{a}$ and $\mathrm{b}$ ) which is not consistent with the AVO behaviour on the original seismic data. Therefore, a thinner layer with changing fluids is more likely to be the cause of the high amplitude anomalies as discussed in section 6.2.1.
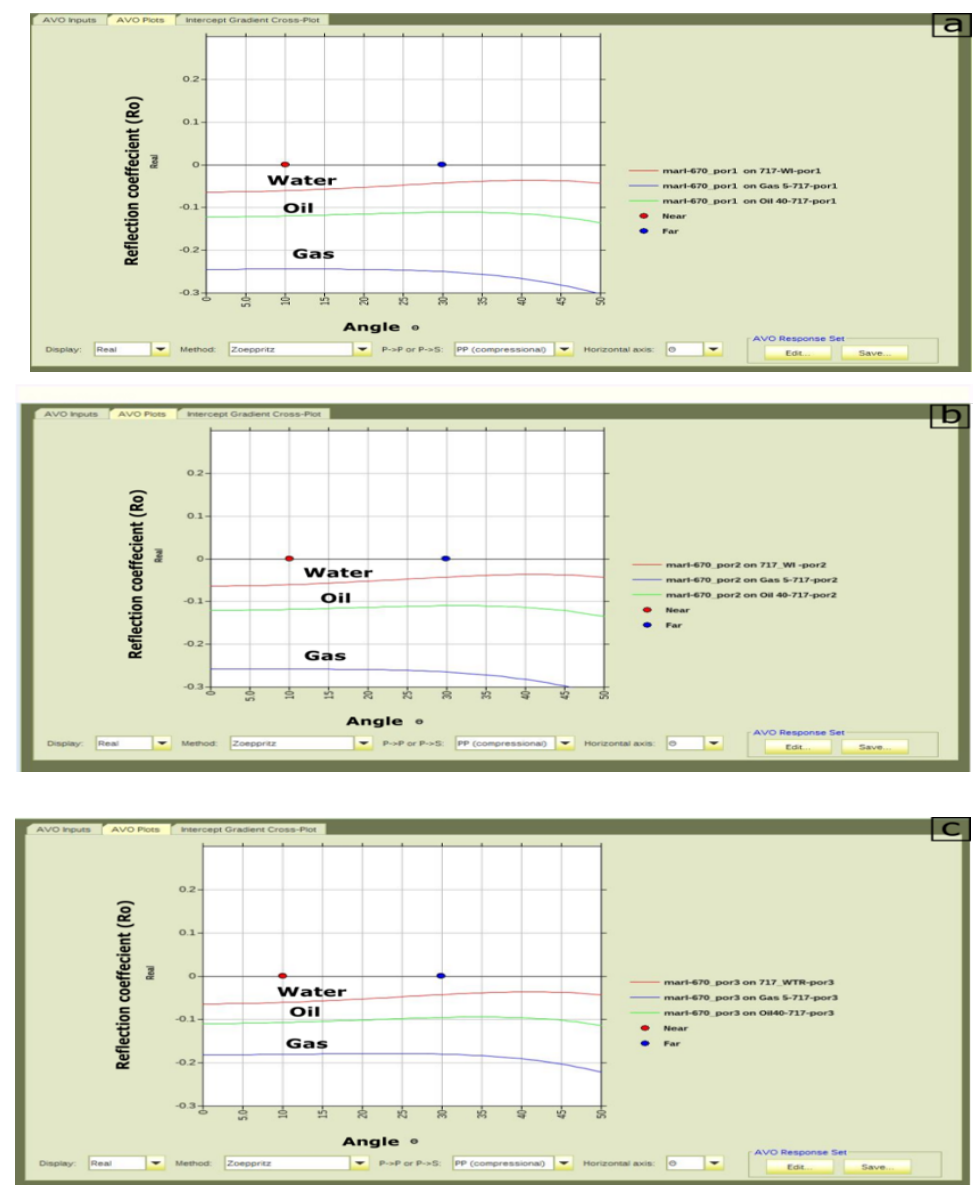

Fig. 11.AVO plots show the Reflection coefficient (R0) variation with angle $\Theta$ within the target horizon-A with three different porosity ranges $(0.2606,0.4606,0.1606)$ from the original one $(0.3606)$. Note:that changing the porosity has little effect on the amplitude variation with offset which give the same AVO behavior, a negative intercept decreasing with offset. 

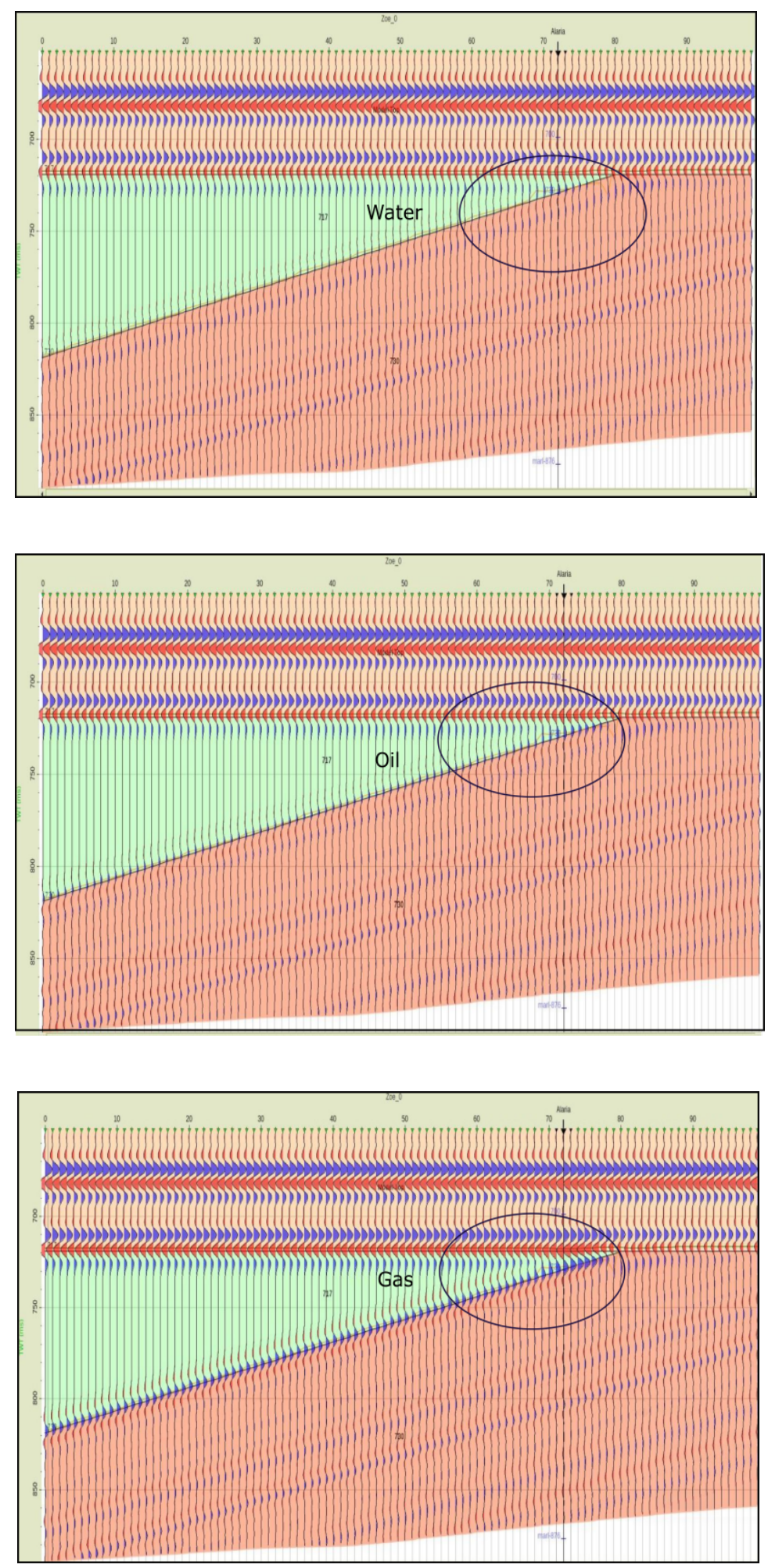

Fig. 12. a,b and c. Synthetic seismogram for the wedge model by using zero-offset Ricker wavelet of $55 \mathrm{~Hz}$ Frequency within the interesting zone. a. wedge model for water; b. wedge model for oil; c. wedge model for gas. 

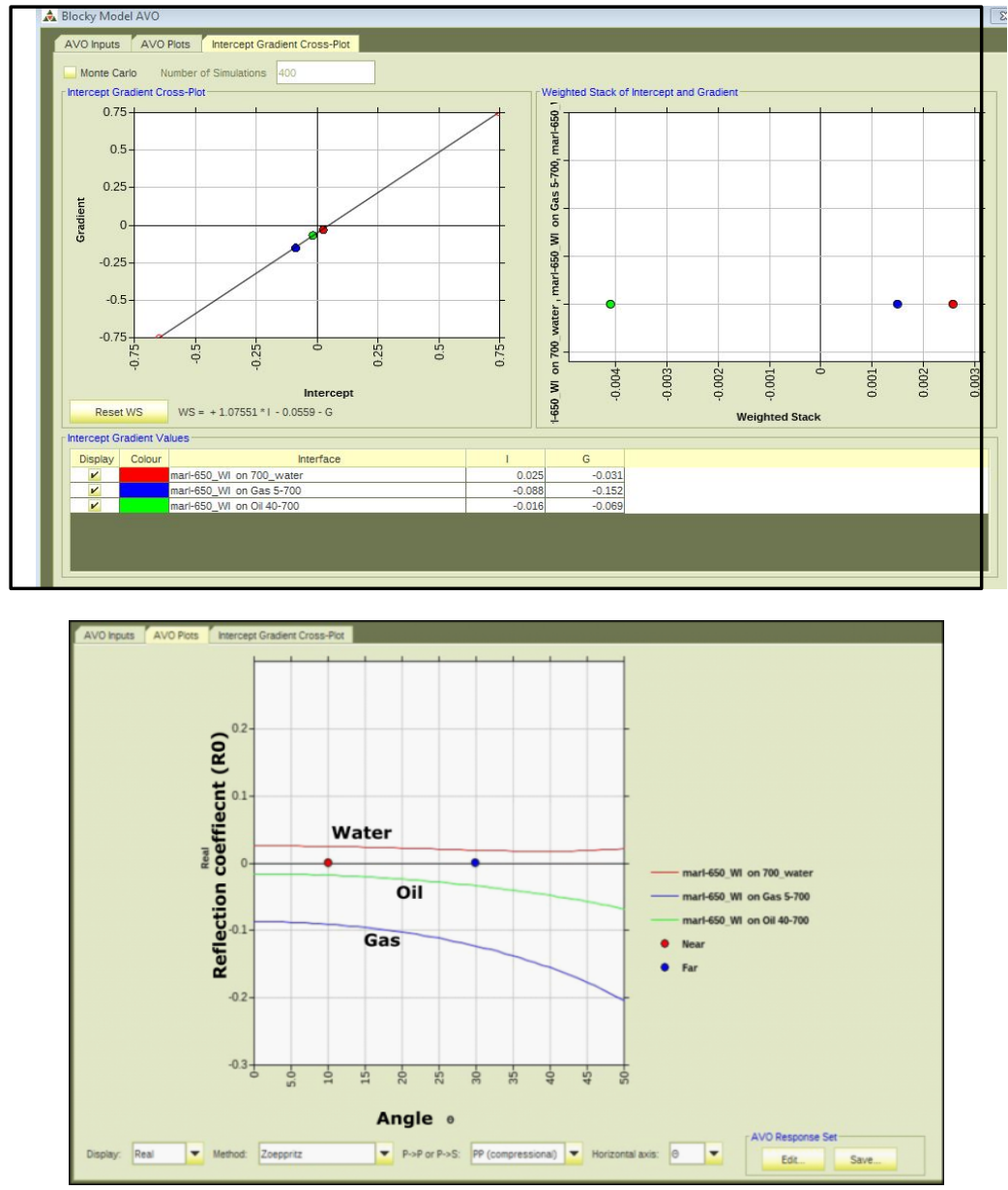

Fig.13. a. AVO cross plot of intercept and gradient shows different AVO characteristics compared with the AVO behaviour of the AVO result from the original prestack seismic data and the seismic synthetic in figures ( 7and 8 ) shown in ; b.

AVO plots show the Reflection coefficient (R0) variation with angle $\Theta$.

\section{Conclusion}

The aim of this study was to investigate the existence of the high amplitude anomaly that has been recognised on the 3D stacked time migrated data in the Laminaria high. AVO analysis was applied to the 2D prestack data to confirm the AVO behaviour of the high amplitude anomalies or bright spots that have been interpreted as an indication of hydrocarbon leakage in the Laminaria High. AVO cross plots from the real pre-stack seismic data show AVO class IV as it gives a negative intercept decreasing with offset. This result matches our AVO result of fluid substitution for the seismic synthetics. From this result, it is concluded the high amplitude anomaly on the seabed and the target horizon 9 is the result of changing the fluid and the lithology content along the target horizons. It is noticed that changing the porosity has little effect on the amplitude variation with offset. Finally, a small change of thickness caused a change in the amplitude; however, this change in thickness gives different AVO characteristics. Therefore, a thinner layer with changing fluids is more likely to be the cause of the high amplitude anomalies. 


\section{ACKNOWLEDGEMENTS}

Special thanks to the Geoscience Australia for providing the 2D seismic and well data: http://www.ga.gov.au/nopims.

\section{References}

Abbassi, S., Primio, R., Horsfield, B., Edward, D., Volk, H., Anka, Z., \& George, S., (2015). On the filling and leakage of petroleum from traps in the Laminaria High region of the northern Bonaparte Basin, Australia. Marine and Petroleum Geology. (59)91-113. https://doi:S0264817214002554.

Abdulkareem, L., Imber, J., \& Hobbs, R. (2019). Geophysical evidence for structurally controlled, authigenic carbonate cementation in the Laminaria High, Bonaparte Basin, Northwest Shelf of Australia. Marine and Petroleum Geology, (99)563-576.

Arun, K. P., Sain, K., \& Kumar, J. (2020). Application of constrained AVO inversion: 2-D modelling of gas hydrates and free gas in Mahanadi basin, India. Journal of Natural Gas Science and Engineering, (78), 103287.

Bakhtiari, S. R., Farahbakhsh, E., \& Moghadam, R. H. (2014). Application of AVO Attributes and Fluid Replacement in Determining AVO Anomaly; Case Study of Aboozar Oil Field, Iran. Journal of Tethys., 2(3), 242-253.

Castagna, J.P. \& Backus, M.M. (1993). AVO analysis-tutorial and review in Castagna, J. and Backus, M.M., eds, Offset-dependent reflectivity. Theory and practice of AVO analysis: Soc. Expl. Geophys., 3-37.

Castagna, J.P. \& Swan, H.W. (1997). Principles of AVO cross plotting: AAPG Mid-Continent Section Meeting; Abstracts; AAPG Bulletin, (81)8, 1348.

Castagna, J. P., \& Swan, H. W. (1997). Principles of AVO crossplotting. The leading edge, 16(4), 337-344.

Ciftci, N.B., Langhi, L., (2012). Evolution of the hourglass structures in the Laminaria High, Timor Sea: Implications for hydrocarbon traps. Journal of Structural Geology. (36), 55-70.

Chacko, S. (1989). Porosity identification using amplitude variations with offset: Examples from South Sumatra. Geophysics. (54)8 942-951.

Chopra, S., \& Castagna, J. P. (2014). Avo. Society of Exploration Geophysicists.Pp.340 
De Ruig, M.J., Trupp, M., Bishop, D.J., Kuek,D., \& Castillo, D.A., (2000). Fault architecture and the mechanics of fault reactivation in the Nancar Trough/Laminaria area of the Timor Sea. APPEA Journal, pp.174-193.

Douglas J. Foster; Robert G. Keys; \&F. David Lane. (2010). Interpretation of AVO anomalies Geophysics 75(5) 75A3-75A13.

Dyt, C.P., Langhi, L., \& Bailey, W.P., (2012). Automating conceptual models to easily assess trap integrity and oil preservation risks associated with fault reactivation. Mar. Pet. Geol,(30), 81-97.

Farfour M, Yoon WJ, \& Kim J. (2015) Seismic attributes and acoustic impedance inversion in interpretation of complex hydrocarbon reservoirs. J Appl Geophys.(114)68-80.

Foster, D.J., Keys, R.G. \& LaneF.D.(2010). Interpretation of AVO anomalies. Geophysics. (75)5, $75 \mathrm{~A} 3-75 \mathrm{~A} 13$

Gartrell, A., Zhang, Y., Lisk, M., \& Dewhurst, D., 2003. Enhanced hydrocarbon leakage at fault intersections: an example from the Timor Sea, Northwest Shelf, Australia. Journal of Geochemical Exploration., (78-79) 361-365.

Gartrell, A., Zhang, Y., Lisk, M. \& Dewhurst, D., (2004). Fault intersections as critical hydrocarbon leakage zones: integrated field study and numerical modelling of an example from the Timor Sea, Australia. Mar. Petrol. Geol., (21), 1165-1179.

Gartrell, A., W. R. Bailey, \& M. Brincat, (2005). Strain localisation and trap geometry as key controls on hydrocarbon preservationin the Laminaria High area: APPEA Journal., (45), 477-492.

Gartrell, A., Bailey, W.R. \& Brincat, M., (2006). A new model for assessing trap integrity and oil preservation risks associated with postrift fault reactivation in the Timor Sea. AAPG Bulletin., (90), 1921-1944.

Guan, Z., Sheng, Y.N., Luo, M., Xu, Y., Zhang, B. \& Wang, Q., (2018). A new quantitative evaluation method for drilling risk based on uncertainty analysis. Kuwait Journal of Science, 45(3).

Han, D., Batzle, M.L., (2004). Gassmann's equation and fluid-saturation effects on seismic velocities. Geophysics. (69), 398-405.

Han, D. (1992). Fluid saturation effect on rock velocities in seismic frequencies. Presented at the SEGEAEG Summer Research Workshop, Big Sky, Montana, USA, 9-14 August.

Langhi, L. \& Borel, G.D., (2008). Reverse structures in accommodation zone and early compartmentalization of extensional system, Laminaria High (NW shelf, Australia). Marine and Petroleum Geology., (25), 791-803. 
Langhi, L., Ciftci, N.B., \& Borel, G.D. 2011. Impact of lithospheric flexure on the evolution of shallow faults in the Timor foreland system. Marine Geology., (284) 40-54.

Li, Y., \& Downton, J. (2000). The applications of amplitude versus offset in carbonate reservoir: Reexamining the potential. In SEG Technical Program Expanded Abstracts 2000 (166-169). Society of Exploration Geophysicists.

Li, Y., Goodway, B., \& Downton, J. (2003). Recent advances in application of AVO to carbonate reservoirs. Cseg Recorder, (28), 34-40.

Loizou, N., Liu, E., \& Chapman, M. (2008). AVO analyses and spectral decomposition of seismic data from four wells west of Shetland, UK. Petroleum Geoscience, 14(4), 355-368.

Miller, S. L., \& Stewart, R. R. (1990). Effects of lithology, porosity and shaliness on P-and S-wave velocities from sonic logs. Canadian Journal of Exploration Geophysics, 26(1-2), 94-103.

Montazeri,M., (2013). Reprocessing of 2D Reflection Seismic Marine Data and Investigation into the AVO behavior of Cambrian Sandstones, Southern Baltic Sea, Sweden. Independent thesis Advanced level (degree of Master), Uppsala University, Disciplinary Domain of Science and Technology, Earth Sciences, Department of Earth Sciences, Geophysics.

Mughal, M. R., \& Akhter, G. (2020). Amplitude variation with offset (AVO) analysis via fluid replacement modeling (FRM) for characterizing the reservoir response of Cretaceous sand interval. Nafta-Gaz, (76).

Pan, W., \& Innanen, K. A. (2013). AVO/AVF analysis of thin beds in elastic media. In SEG Technical Program Expanded Abstracts 2013(373-377). Society of Exploration Geophysicists.

Partyka, G., J. Gridley, J., \& Lopez, (1999). Interpretational applications of spectral decomposition in reservoir characterization: The Leading Edge.,(18),353-354. https://doi:10.1190/1.1438295.

Puryear, C. I., \& Castagna, J. P. (2008). Layer-thickness determination and stratigraphic interpretation using spectral inversion: Theory and application. Geophysics, 73(2), R37-R48.

Rizwan M, Akhter G, Mustafa A, Bin Nisar U, \& Ashfaq K (2018) .Amplitude versus ofset (AVO) modelling and analysis for quantitativeinterpretation of porosity and saturation: a case study for Sawangas feld, middle Indus basin. Pakistan Geofísica internacional.57(2):151-160

Ross, C. P., Kinmann, D. L. (1995). Non-bright spot AVO; two examples. Journal of Geophysics. (60), 1398-1408.

Rutherford, S., Williams, R. (1989). Amplitude-versus-offset variations in gas sands. Journal of Geophysics. (54), 680-688. 
Saeed, W., Zhang, H., Guo, Q., Ali, A., Azeem, T., Toqeer, M.\& Hussain, M. (2020). An integrated petrophysical-based wedge modeling and thin bed AVO analysis for improved reservoir characterization of Zhujiang Formation, Huizhou sub-basin, China: A case study. Open Geosciences, 12(1), 256-274.

Saqab, M. M., \& Bourget, J. (2015). Structural style in a young flexure-induced oblique extensional system, north-western Bonaparte Basin, Australia. Journal of Structural Geology, (77), 239-259.

Saqab, M. M., Bourget, J., Trotter, J., \& Keep, M. (2017). New constraints on the timing of flexural deformation along the northern Australian margin: implications for arc-continent collision and the development of the Timor Trough. Tectonophysics, (696), 14-36.

Smith, G.C., Tilbury, L.A., Chatfield.A, Senycia, a\& P,Thompson, N.,(1996). Laminaria - A new Timor Sea discovery: Australian Petroleum Production and Exploration Association Journal, (36), 1228.

Verm, R. W., Hilterman, F. J. (1994). Lithologic color-coded sections by AVO crossplots. 64th Society of Exploration Geophysicists Meeting.

Wandler A, Evans B, Link C (2007). AVO as a fluid indicator: a physical modelling study. Geophysics. (72):C 9-C 17.

Widess M. (1973). How thin is a thin bed? Geophysics. ;(38).1176-80.

Yilmaz, OZ. (2001). Seismic data analysis: processing, inversion, and interpretation of seismic data. Investigations in geophysics, 2nd edition, Volume I. Tulsa, OK, Society of Exploration Geophysicists.

Submitted: $17 / 02 / 2021$

Revised: $\quad 01 / 06 / 2021$

Accepted: $13 / 06 / 2021$

DOI: $\quad 10.48129 / \mathrm{kjs} .12351$ 